\title{
Milk nutrition and childhood epilepsy: An ex vivo study on cytokines and oxidative stress in response to milk protein fractions
}

\author{
M. Albenzio, ${ }^{* 1}$ A. Santillo, ${ }^{*}$ M. G. Ciliberti, ${ }^{*}$ L. Figliola, ${ }^{*}$ M. Caroprese,${ }^{*}$ A. N. Polito, $†$ and G. Messinał \\ *Department of the Sciences of Agriculture, Food and Environment (SAFE), University of Foggia, Via Napoli, 25, 71100 Foggia, Italy \\ †Complex Structure of Neuropsychiatry Childhood-Adolescence of Ospedali Riuniti of Foggia, Viale Pinto, 71100 Foggia, Italy \\ ‡Department of Clinical and Experimental Medicine, University of Foggia, Foggia, Viale Pinto, 71100 Foggia, Italy
}

\section{ABSTRACT}

We present a pilot study on the effects of milk protein fractions $\left[\alpha_{\mathrm{S}_{1}}\right.$-casein $(\mathrm{CN}), \alpha_{\mathrm{S}^{2}} \mathrm{CN}, \kappa-\mathrm{CN}, \beta-\mathrm{CN}$, and a mix of $\alpha$-lactalbumin $(\alpha-\mathrm{LA})$ and $\beta$-lactoglobulin $(\beta-\mathrm{LG})]$ from different animal species (bovine, ovine, and caprine) on pro- and anti-inflammatory cytokines and oxidative status in cultured peripheral blood mononuclear cells from children with generalized epilepsy. Peripheral blood mononuclear cells (PBMC) were obtained by density gradient from blood of 10 children with generalized epilepsy ( 5 males; mean age $33.6 \pm 5.4$ mo) and 10 controls (5 males; mean age $35.6 \pm 6.8 \mathrm{mo}$ ). Children with epilepsy were grouped according to cytokine levels as follows: children with epilepsy having low levels of cytokines not different from those of control children (LL-EC); children with epilepsy having cytokine levels at least 5-fold higher (medium levels) than those of control children (ML-EC); and children with epilepsy having cytokine levels at least 10-fold higher (high levels) than those of control children (HL-EC). The production of tumor necrosis factor- $\alpha$ (TNF- $\alpha$ ), IL-10, IL-6, and IL-1 $\beta$ was studied in cultured PBMC incubated with $\alpha_{\mathrm{S}^{-}} \mathrm{CN}, \alpha_{\mathrm{S} 2}-\mathrm{CN}, \kappa-\mathrm{CN}, \beta-\mathrm{CN}$, and a mix of $\alpha-\mathrm{LA}$ and $\beta-\mathrm{LG}$ from bovine, caprine, and ovine milks. The levels of reactive oxygen and nitrogen species (ROS/RNS) and catalase activity were assessed in cultured supernatant. In the HL-EC group, $\beta-\mathrm{CN}$ from small ruminant species (ovine and caprine) induced the highest levels of TNF- $\alpha$, whereas PBMC incubated with $\alpha_{\mathrm{S}_{2}} \mathrm{CN}$ from ovine milk and the mix of $\beta-\mathrm{LG}$ and $\alpha$-LA from all tested milk species had the lowest levels of TNF- $\alpha$. Within the HL-EC group, production of IL$1 \beta$ was higher for bovine and ovine $\alpha_{\mathrm{S}_{2}} \mathrm{CN}$ fractions and lower for caprine and ovine $\beta-\mathrm{CN}$ and $\kappa-\mathrm{CN}$. In the HL-EC group, IL-6 was higher in cultured PBMC in-

Received May 22, 2017.

Accepted January 14, 2018.

${ }^{1}$ Corresponding author: marzia.albenzio@unifg.it cubated with $\alpha_{\mathrm{S}^{2}} \mathrm{CN}$ from bovine and ovine milk than from caprine milk. The cytokine IL-10 did not differ among milking species. The highest levels of ROS/RNS were found after incubation of PBMC with the $\beta$-CN fraction in bovine milk. Catalase activity was higher in PBMC cultured with $\beta-\mathrm{CN}$ isolated from bovine and caprine milk and with $\alpha_{\mathrm{S} 1}-\mathrm{CN}$ from ovine milk.

Key words: milk protein, childhood epilepsy, cytokine, oxidative stress

\section{INTRODUCTION}

Epilepsy is the third most common brain disorder, and it is characterized by a persistent predisposition to seizures and by emotional and cognitive dysfunction (Duncan et al., 2006). Overwhelming evidence indicates that epilepsy is associated with inflammation and elevated levels of cytokines (Galic et al., 2012). Cytokines are immunological molecules involved in the progression of many diseases (Damsgaard et al., 2009); different cytokine patterns can be used to characterize immune responses such as immune maturation, allergic tendencies in infancy, and later development of autoimmune disease (Gutcher and Becher, 2007).

Inflammation of the central nervous system is characterized by microglial activation with an increase in pro-inflammatory cytokines such as tumor necrosis factor- $\alpha$ (TNF- $\alpha$ ), IL-1 $\beta$, and IL-6 (Riazi et al., 2010). Seizures not only induce the expression of cytokines in the brain but also alter peripheral cytokine levels ( $\mathrm{Li}$ et al., 2011); indeed, peripheral inflammation reflects a similar inflammatory state in the brain (Riazi et al., 2010). The involvement of the blood-brain barrier and its dysfunction in epileptic syndromes suggest that blood-brain barrier failures precede and are required for the initiation of status epilepticus (Marchi et al., 2009).

A role of diet in triggering epilepsy disorders has been claimed, and research has focused on the relationship between epilepsy and modulation of the gut-brain axis, brain inflammatory reactions, and dietary allergic dis- 
orders (Albenzio et al., 2016a). Autoimmune processes and associated pathogenic autoantibodies have received increasing attention for their role in epilepsy disorders (Palace and Lang, 2000; Pollak et al., 2014).

A population-level epidemiological study documented that epilepsy and some autoimmune diseases frequently co-occur, and the potential role of autoimmunity in epilepsy must be considered (Ong et al., 2014). Of particular interest are the many species of intestinal microbes that reside in great numbers in the digestive tract. These gut microbiota may play a vital role not only in the maintenance of microbiota homeostasis and food digestion, but also in the progression of autoimmune diseases through modulation of immune responses (Albenzio et al., 2016b; Wu et al., 2016).

In a prospective study based on pediatric experience, a link between cow milk allergy and epileptic events was reported (Falsaperla et al., 2014). In childhood, milk nutrition is particularly relevant because human newborn milk fulfils nutritional needs and ensures safe development and growth during the first stages of life (Albenzio et al., 2016a).

In a previous study, we investigated the role of bovine, ovine, and caprine milk, caseins, and whey proteins on the immune status of children with generalized epilepsy; cytokines and reactive oxygen and nitrogen species (ROS/RNS) detected ex vivo were useful biomarkers to discriminate the effects of milk components on epilepsy in children (Albenzio et al., 2016b).

The present study was undertaken to evaluate the effects of milk protein fractions $\left(\alpha_{\mathrm{S}^{-}} \mathrm{CN}, \alpha_{\mathrm{S} 2}-\mathrm{CN}, \kappa-\mathrm{CN}\right.$, $\beta-\mathrm{CN}$, and a mix of $\alpha-\mathrm{LA}$ and $\beta-\mathrm{LG}$ ) from different animal species (bovine, ovine, and caprine), on pro- and anti-inflammatory cytokines and oxidative status in cultured peripheral blood mononuclear cells (PBMC) from children with generalized epilepsy.

\section{MATERIALS AND METHODS}

\section{Patients}

Ten children with generalized epilepsy ( 5 male, 5 female; mean age $34.6 \pm 4.4 \mathrm{mo}$ ) and 10 controls (5 male, 5 female; mean age $36.5 \pm 5.8 \mathrm{mo}$ ) were recruited at the Complex Structure of Neuropsychiatry ChildhoodAdolescence of Ospedali Riuniti (Foggia, Italy) and included in the study. Inclusion and exclusion criteria were in accordance with those reported in Albenzio et al. (2016b). Approval was obtained from the Ospedali Riuniti (Foggia, Italy) Institutional Review Board for these studies. Written informed consent was obtained from the parents in accordance with the Declaration of
Helsinki on the Ethical Principles for Medical Research Involving Human Subjects.

\section{Separation of Milk Proteins by Reversed-Phase HPLC}

Samples from pasteurized bovine, ovine, and caprine milks were prepared following the method proposed by Bobe et al. (1998). Briefly, aliquots of $500 \mu \mathrm{L}$ of milk were frozen at $-20^{\circ} \mathrm{C}$. A solution containing $0.1 \mathrm{M}$ Bis-Tris buffer (pH 6.8), $6 \mathrm{M}$ guanidine hydrochloride, $5.37 \mathrm{~m} M$ sodium citrate, and $19.5 \mathrm{~m} M$ dithiothreitol (pH 7) was added to frozen aliquots in a 1:1 ratio (vol: vol). Samples were incubated for $1 \mathrm{~h}$ at room temperature, and centrifuged for $5 \mathrm{~min}$ at $16,000 \times \mathrm{g}$ in a microcentrifuge. The fat layer was then removed with a spatula, and the remaining solution was diluted in a 1:3 ratio (vol:vol) with a solution containing $4.5 \mathrm{M}$ GndHCl prepared in acetonitrile, water, and trifluoroacetic acid (TFA) in a ratio 100:900:1 (vol:vol:vol, $\mathrm{pH}$ 2 ). For the identification of milk proteins, a standard was prepared containing purified bovine milk proteins $\left(\alpha_{S^{-}} \mathrm{CN}, \beta-\mathrm{CN}, \kappa-\mathrm{CN}, \alpha-\mathrm{LA}\right.$, and $\beta-\mathrm{LG}$, purchased from Sigma-Aldrich, St. Louis, MO). Separation of milk proteins was achieved by reversed-phase (RP)-HPLC. The HPLC system consisted of an Agilent 1260 Infinity Series chromatograph (Agilent Technologies, Santa Clara, CA), equipped with a binary pump (Agilent 1260 Infinity series, G1312B), a diode-array detector (Agilent 1260 Infinity series,1315C), and a fraction collector (Agilent 1260 Infinity series, G1364C). The equipment was controlled by the Agilent Chem-Station for LC Systems software. Separations were performed on an RP semi-preparative column C8 (Zorbax-300SB-C8 RP, Agilent Technologies), with a silica-based packing $(5 \mu \mathrm{m}, 300 \AA, 250 \mathrm{~mm} \times 9.4 \mathrm{~mm}$ internal diameter). Gradient elution was carried out with a mixture of 2 solvents. Solvent A consisted of $0.1 \%$ TFA in water and solvent B was $0.1 \%$ TFA in acetonitrile. Separations were performed with the following gradient: linear gradient from 33 to $35 \%$ B in 5 min, from 35 to $37 \%$ B in 4 min, from 37 to $40 \%$ B in 9 min, from 40 to $41 \%$ B in $4 \mathrm{~min}$, followed by an isocratic elution at $41 \% \mathrm{~B}$ during $5.5 \mathrm{~min}$, followed by a linear gradient from 41 to $43 \%$ B in $0.5 \mathrm{~min}$, returning to the starting condition in $1 \mathrm{~min}$, and re-equilibrating the column for $8 \mathrm{~min}$. The flow rate was $2 \mathrm{~mL} / \mathrm{min}$, and column temperature was kept at $45^{\circ} \mathrm{C}$, and detection was made at a wavelength of 214 $\mathrm{nm}$. The injection volume was $80 \mu \mathrm{L}$. Separated protein fractions were collected through the fraction collector, frozen at $-80^{\circ} \mathrm{C}$, and finally freeze-dried. Figure 1 shows the RP-HPLC profile of ovine milk displaying 
peaks attributed to $\kappa-\mathrm{CN}, \alpha_{\mathrm{S}^{2}} \mathrm{CN}, \beta-\mathrm{CN}, \alpha_{\mathrm{S}^{-}} \mathrm{CN}$, and the mix of $\alpha-\mathrm{LA}$ and $\beta-\mathrm{LG}$ according to elution time.

\section{SDS-PAGE of Milk Protein Fractions}

The milk protein fractions collected by RP-HPLC were subjected to electrophoretic separation to confirm the presence and purification of the isolated protein. Sodium dodecyl sulfate PAGE was performed according to Laemmli (1970). The same standards used in RP-HPLC analysis were loaded onto the SDS gels to allow comparison with a reference protein. The gels were stained with Coomassie Brillant Blue G250 (Bio-Rad, Watford, UK), and destained in an aqueous solution of acetic acid and methanol $(20 \%$ and $7 \%$, vol/vol, respectively). The destained gels were acquired using a Gel Doc EQ system (Bio-Rad). Figure 2 shows the SDS-PAGE electrophoretogram of the protein fraction collected by RP-HPLC analysis from ovine milk. The electrophoretogram is given as an example to show the successful separation of the main protein fractions in milk from different species.

\section{Analysis of Cytokines in Cultured PBMC}

Production of TNF- $\alpha$, IL-10, IL-6, and IL-1 $\beta$ was studied in PBMC from blood of patients and control children, incubated with $100 \mu \mathrm{g} / \mathrm{mL}$ of $\kappa-\mathrm{CN}, \alpha_{\mathrm{S1}}-\mathrm{CN}$, $\alpha_{S_{2}} \mathrm{CN}, \beta-\mathrm{CN}$, and a mix of $\alpha-\mathrm{LA}$ and $\beta-\mathrm{LG}$ obtained from bovine, caprine, and ovine milks according to the procedure previously described in Albenzio et al. (2016b). Briefly, PBMC were obtained by Ficoll-His- topaque (Sigma Aldrich, Milan, Italy) density gradient from heparinized venous blood of 10 children with generalized epilepsy and 10 children without clinical signs of disease as controls. The trypan blue dye exclusion test was applied to check PBMC viability, which was $>90 \%$. Finally, $1.5 \times 10^{5} \mathrm{PBMC} / \mathrm{mL}$ were resuspended in RPMI-1640 medium (Sigma Aldrich) supplemented with L-glutamine, penicillin/streptomycin, and 10\% fetal bovine serum (Sigma Aldrich), distributed into 96well microtiter plates, and cultured for $5 \mathrm{~d}$ in $5 \% \mathrm{CO}_{2}$ in a humidified incubator. The PBMC were incubated with $100 \mu \mathrm{g} / \mathrm{mL}$ (final concentration) of $\kappa-\mathrm{CN}, \alpha_{\mathrm{S}_{1}-\mathrm{CN}}$, $\alpha_{S_{2}-} \mathrm{CN}, \beta-\mathrm{CN}$, or a mix of $\alpha-\mathrm{LA}$ and $\beta-\mathrm{LG}$ obtained from bovine, caprine, and ovine milks. At the end of the incubation time, supernatants were harvested and stored at $-20^{\circ} \mathrm{C}$ until cytokine assays were performed using Luminex Multiplex Assays (Thermo Fisher Scientific, Waltham, MA) at Labospace (Milan, Italy). Assays were performed by an independent laboratory.

\section{Determination of ROS/RNS and Catalase Activity}

The levels of ROS and RNS were detected in accordance with Albenzio et al. (2016b) using an OxiSelect in vitro ROS/RNS Assay Kit with Green Fluorescence (Cell Biolabs Inc., San Diego, CA).

The amount of catalase was measured using Human CAT ELISA Kit (Wuhan Fine Biotechnology Co. Ltd., Hubei, China) according to the manufacturer's instructions. Data were expressed in pictograms per milliliter and normalized to protein level (measured by BCA Protein Assay Kit, Thermo Scientific, Rockford, IL).

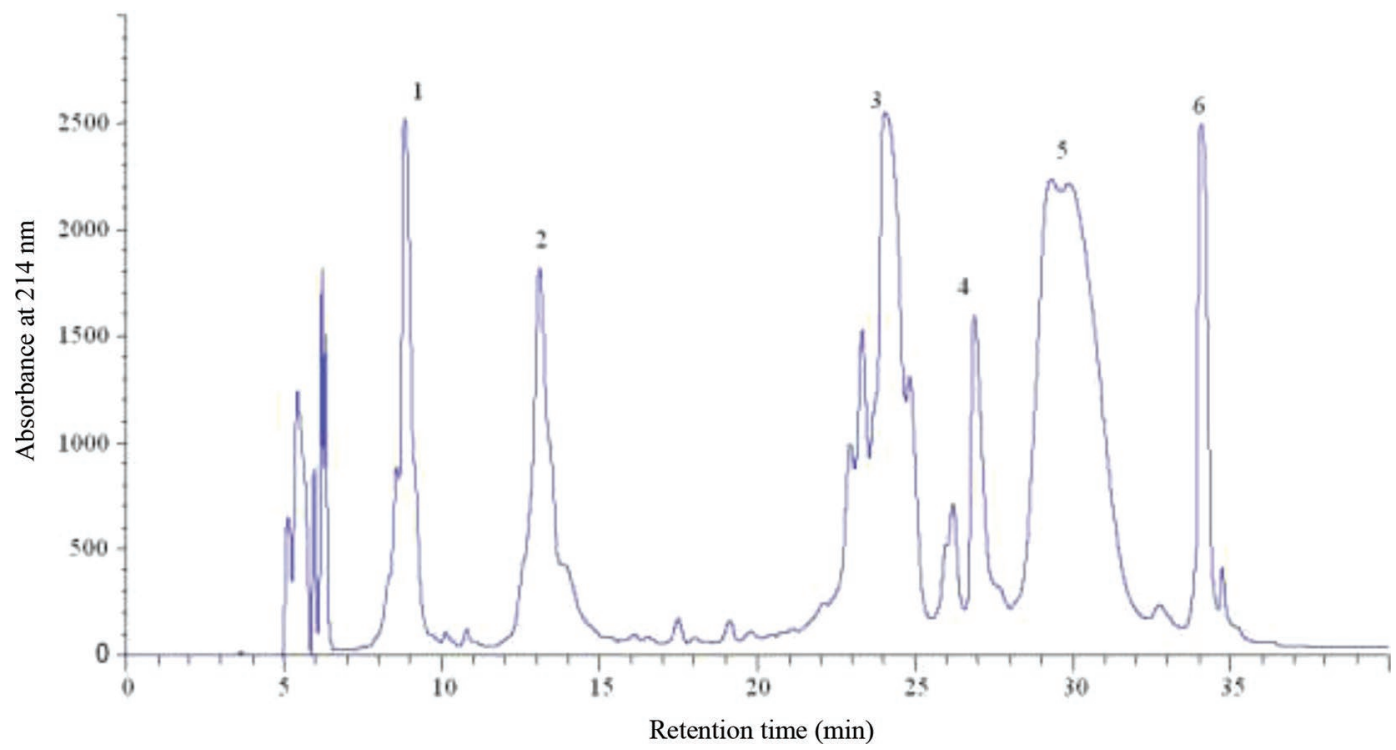

Figure 1. Reverse phase-HPLC profile of ovine milk (as a representative example of results from all milks). Peaks: $1=\kappa-\mathrm{CN} ; 2=\alpha_{\mathrm{S2}}{ }^{-\mathrm{CN}}$; $3=\alpha_{\mathrm{S} 1}-\mathrm{CN} ; 4=$ mix of $\alpha$-LA and $\beta$-LG; 5 and $6=\beta$-CN. Color version available online. 
A

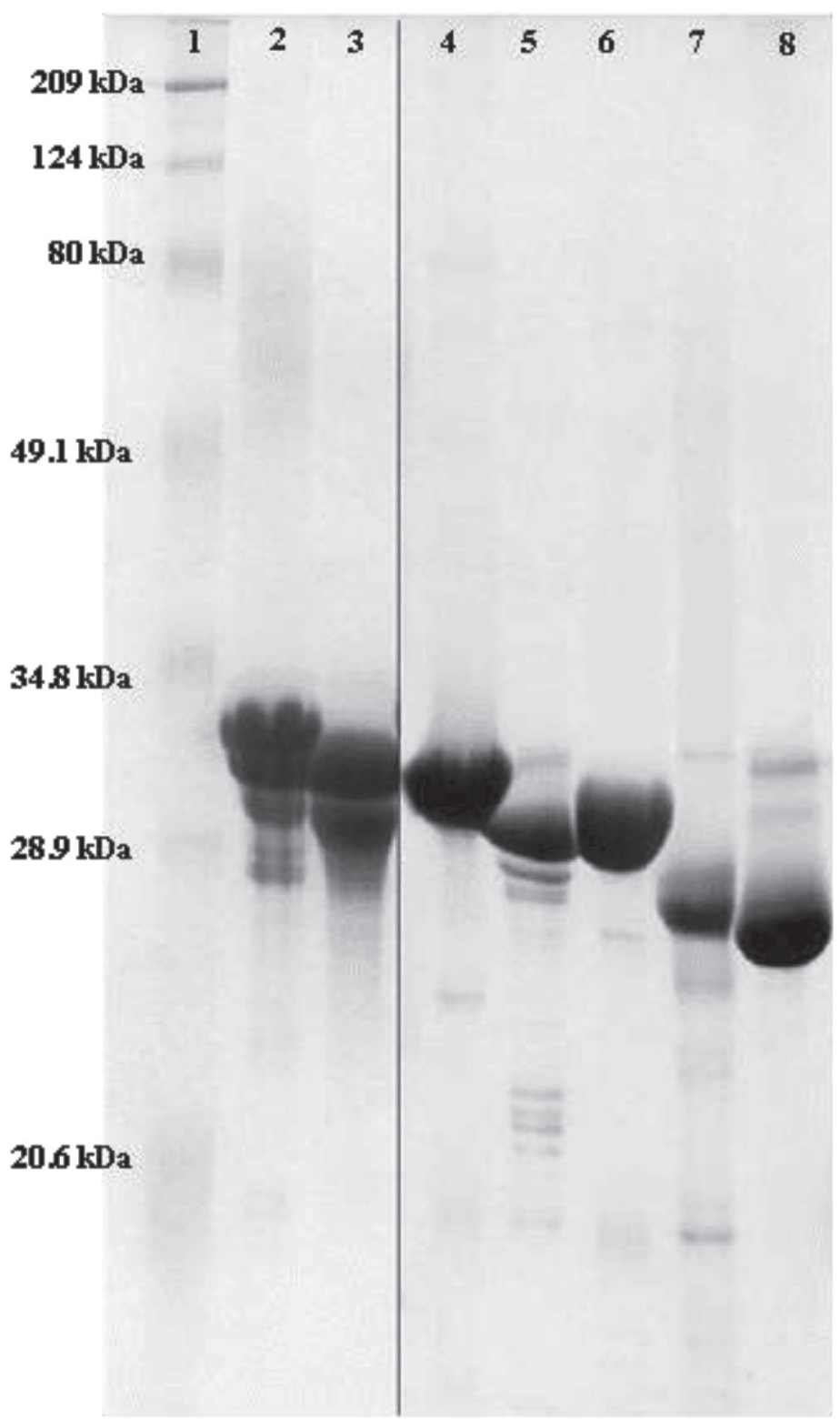

B

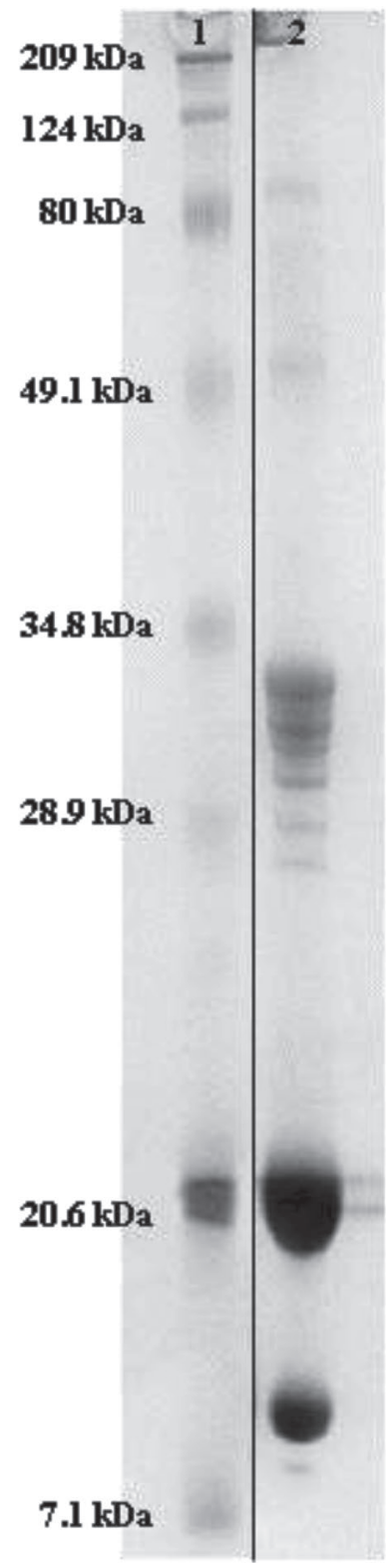

Figure 2. Sodium dodecyl sulfate-PAGE electrophoretogram of the milk protein fractions collected by reverse phase-HPLC. (A) $12 \%$ SDSPAGE: lane $1=$ molecular weight standard; lanes $2,5,7=$ bovine milk proteins $\left(\alpha_{\mathrm{S}^{-}} \mathrm{CN}, \beta-\mathrm{CN}, \kappa-\mathrm{CN}\right.$, respectively); lanes $3,4,6,8=$ ovine milk proteins $\left(\alpha_{\mathrm{S}^{2}} \mathrm{CN}, \alpha_{\mathrm{S}^{-}} \mathrm{CN}, \beta-\mathrm{CN}, \kappa-\mathrm{CN}\right.$, respectively. (B) SDS-PAGE $15 \%$ : lane $1=$ molecular weight standard; lane $2=$ ovine milk proteins $(\beta-\mathrm{LG}$ and $\alpha-\mathrm{LA})$.

\section{Statistical Analysis}

All variables were tested for normal distribution using the Shapiro-Wilk test (Shapiro and Wilk, 1965). Data on cytokines, ROS/RNS, and catalase were analyzed by ANOVA using the GLM procedure of SAS Institute (2011). The effects on patients of experimental factors (species: bovine, caprine, and ovine; and milk protein fraction: $\kappa_{-} \mathrm{CN}, \alpha_{\mathrm{S}^{-}} \mathrm{CN}, \alpha_{\mathrm{S} 2}-\mathrm{CN}, \beta-\mathrm{CN}$, and $\alpha-\mathrm{LA}$ and
$\beta$-LG mix) and their interaction were tested for cytokine levels, catalase, and ROS/RNS according to the following model:

$$
\mathrm{y}_{\mathrm{ijk}}=\mu+\alpha_{\mathrm{i}}+\beta_{\mathrm{j}}+(\alpha \beta)_{\mathrm{ij}}+\varepsilon_{\mathrm{ijk}}
$$

where $y_{i j k}$ is the dependent variable; $\mu$ is the overall mean; $\alpha$ is the effect of animal species $(i=1-3) ; \beta$ is 
the effect of milk protein fraction $(\mathrm{j}=1-5)$; $\alpha \beta$ is the interaction of the animal species $\times$ milk protein fraction; and $\varepsilon$ is the error.

For cytokine response, patients were grouped as follows: LL-EC $(\mathrm{n}=4)=$ group of children with epilepsy having low levels of cytokines not different from those of control children; ML-EC $(\mathrm{n}=3)=$ group of children with epilepsy having cytokine levels at least 5 -fold higher (medium levels) than those of control children; HL-EC $(\mathrm{n}=3)=$ group of children with epilepsy having cytokine levels at least 10-fold higher (high levels) than those of control children. When significant effects were found (at $P<0.05$ ), Student's $t$-test was used to locate significant differences between means.

\section{RESULTS AND DISCUSSION}

\section{Cytokine Pattern in Cultured PBMC}

Monocytic cytokine production can be measured ex vivo in stimulated monocytes isolated from peripheral blood, which is thought to reflect their potential to produce cytokines (Albers et al., 2005; Damsgaard et al., 2009).

Levels of different cytokines in cultured PBMC incubated with $\alpha_{\mathrm{S}^{-}} \mathrm{CN}, \alpha_{\mathrm{S}^{2}} \mathrm{CN}, \kappa-\mathrm{CN}, \beta-\mathrm{CN}$, and the $\alpha-\mathrm{LA}$ and $\beta-\mathrm{LG}$ mix of obtained from bovine, ovine, and caprine milks were measured in children with epilepsy. The percentage distribution of children grouped according to level of cytokines is reported in Table 1. For TNF- $\alpha$, $50 \%$ of children were in LL-EC, $30 \%$ in ML-EC, and $20 \%$ in HL-EC. For IL- $6,50 \%$ of children were in LLEC, $20 \%$ were in ML-EC, and $30 \%$ were in HL-EC. For IL- $1 \beta, 40 \%$ of children were in LL-EC, $30 \%$ were in ML-EC, and 30\% were in HL-EC. Finally, for IL-10, all children were in LL-EC; that is, levels were comparable

Table 1. Percentage distribution of children with epilepsy grouped according to levels of different cytokines in cultured peripheral blood mononuclear cells

\begin{tabular}{lccc}
\hline & \multicolumn{3}{c}{ Group $^{1}$} \\
\cline { 2 - 4 } Cytokine & LL-EC & ML-EC & HL-EC \\
\hline TNF- $\alpha^{2}$ & 50 & 30 & 20 \\
IL-6 & 50 & 20 & 30 \\
IL-1 $\beta$ & 40 & 30 & 30 \\
IL-10 & 100 & - & - \\
\hline
\end{tabular}

${ }^{1}$ LL-EC $(\mathrm{n}=4)=$ group of children with epilepsy having low levels of cytokines not different from those of controls; ML-EC $(\mathrm{n}=3)=$ group of children with epilepsy having cytokine levels at least 5 -fold higher (medium levels) than those of controls; HL-EC $(\mathrm{n}=3)=$ group of children with epilepsy having cytokine levels at least 10-fold higher (high levels) than those of controls.

${ }^{2}$ Tumor necrosis factor- $\alpha$. with those of controls. It is worth noting that half of the children with generalized epilepsy showed TNF- $\alpha$ and IL-6 patterns comparable with those of control children.

Cytokine responses in children are characterized by variable behavior due to the dynamism in the development of the immune system and immune maturation. Furthermore, during weaning, children are challenged to food antigens able to influence expression of cytokines. Albenzio et al. (2016a) reviewed the implications of diet on the modulation of gut-brain axis, brain inflammatory reactions, and dietary allergic disorders in children with epilepsy.

\section{TNF- $\alpha$ Produced by Cultured PBMC of Children with Generalized Epilepsy}

The production of TNF- $\alpha$ by PBMC after incubation with milk protein fractions from different species is reported in Figure 3. In general, concentration of TNF- $\alpha$ was affected by species $(P<0.01)$, protein fraction $(P$ $<0.01)$, and their interaction $(P<0.001)$. The HL-EC group had a lower concentration of TNF- $\alpha$ in PBMC incubated with bovine milk than with ovine or caprine milk $(284.72,336.40$, and $329.78 \pm 10.37 \mathrm{pg} / \mathrm{mL}$; mean \pm SEM from the 3 children with epilepsy enrolled in the HL-EC group, respectively); the results were the same for all of the milk protein fraction tested. The interaction between species and milk protein fractions showed no differences in the concentration of TNF- $\alpha$ in the LL-EC group. In contrast, children in the MLEC group had the highest TNF- $\alpha$ concentrations in response to the ovine $\beta-\mathrm{CN}$ fraction and the lowest in response to the mix of $\beta$-LG and $\alpha$-LA from ovine and caprine milks. In the HL-EC group, $\beta$-CN from ovine and caprine milks induced the highest levels of TNF- $\alpha$, whereas $\alpha_{S_{2}}-\mathrm{CN}$ from ovine milk and the $\alpha$-LA and $\beta$-LG mix from all tested milking species resulted in the lowest levels of TNF- $\alpha$. Riazi et al. (2010) reported that TNF- $\alpha$ may be considered a link between peripheral and central inflammation, suggesting that the production of TNF- $\alpha$ within the brain during peripheral inflammation increases seizure susceptibility. Indeed, blocking production of $\mathrm{TNF}-\alpha$ in the central nervous system was effective as an anticonvulsant mechanism. In a previous ex vivo study, Albenzio et al. (2016b) reported no differences according to species in TNF- $\alpha$ produced by cultured PBMC isolated from children with generalized epilepsy and incubated with the whole casein fraction of bovine, ovine, and caprine milks. In the present study, when casein fractions were isolated and tested on PBMC from children with epilepsy in groups ML-EC and HL-EC, we observed a major ef- 
fect of $\beta-\mathrm{CN}$ from ovine milk on TNF- $\alpha$ production. Sheep milk is the richest of bovine and caprine in casein with a content of approximately $4.18 \mathrm{~g} / 100 \mathrm{~g}$ (Dario et al., 2008); about half as much is present in bovine (2.80 g/100 g; Guo et al., 2007) and caprine (2.81 g/100 g; Leitner et al., 2004) milks. Furthermore, the main individual casein fractions $\left(\alpha_{\mathrm{S1}^{-}}, \alpha_{\mathrm{S} 2^{-}}, \kappa^{-}\right.$, and $\beta-\mathrm{CN})$ are characterized by different levels of synthesis in milk, and their proportions vary according to polymorphic expression of the encoding genes. Whey proteins exhibit genetic polymorphism that influences milk composition; ovine milk has been shown to be the richest in whey proteins $(1.02 \mathrm{~g} / 100 \mathrm{~g})$ compared with other milking species (Dario et al., 2008). In the present study, the differences in TNF- $\alpha$ response after stimulation with different protein fractions may be associated with genetic polymorphism related to differences in polypeptide chains and AA sequences.

\section{IL-1 $\beta$ Produced by Cultured PBMC of Children with Generalized Epilepsy}

The production of IL-1 $\beta$ by PBMC after incubation with milk protein fractions from different species is reported in Figure 4. Interleukin-1 $\beta$ contributes to the development of epilepsy through rapid effects on neuronal survival ad transcription pathways and long-lasting effects on expression of selective gene families involved in brain structural and functional changes (Vezzani and Baram, 2007). The concentration of IL-1 $\beta$ was affected by species $(P<0.001)$, protein fractions $(P<0.001)$, and their interaction $(P<0.01)$. In the LL-EC group, mean values $( \pm \mathrm{SEM})$ of IL-1 $\beta$ were $14.99,14.21$, and $10.82 \pm 1.11 \mathrm{pg} / \mathrm{mL}$ in response to bovine, ovine, and caprine milks, respectively; in the ML-EC group, values were $28.49,23.47$, and $22.05 \pm 1.21 \mathrm{pg} / \mathrm{mL}$, respectively; and in the HL-EC group, values were 58.01, 53.44, and

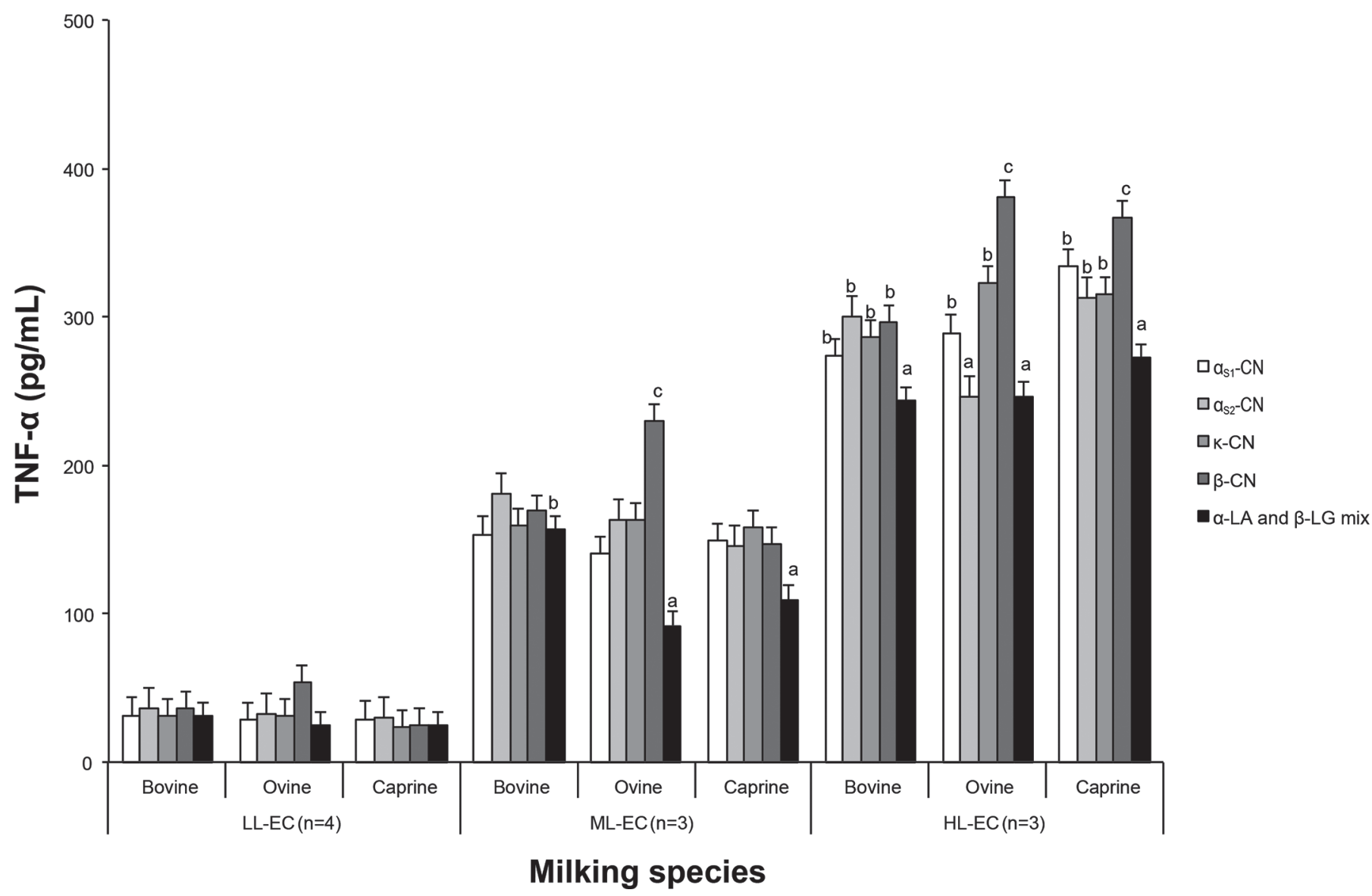

Figure 3. Concentration $(\mu \mathrm{g} / \mathrm{mL})$ of tumor necrosis factor- $\alpha$ (TNF- $\alpha)$ produced by peripheral blood mononuclear cells after incubation with milk protein fractions $\left(\kappa-\mathrm{CN}, \alpha_{\mathrm{S}^{2}} \mathrm{CN}, \alpha_{\mathrm{S} 1}-\mathrm{CN}, \beta-\mathrm{CN}\right.$, and a mix of $\alpha-\mathrm{LA}$ and $\beta$-LG) from different species (bovine, ovine, and caprine). LL-EC $(\mathrm{n}=4)=$ group of children with epilepsy having low levels of cytokines not different from those of control children; ML-EC $(\mathrm{n}=3)=$ group of children with epilepsy having cytokine levels at least 5 -fold higher (medium levels) than those of control children; HL-EC ( $\mathrm{n}=3$ ) $=$ group of children with epilepsy having cytokine levels at least 10-fold higher (high levels) than those of control children. Error bars represent SEM. Mean values with different letters $(\mathrm{a}-\mathrm{c})$ differ within a group and species at $P<0.05$ (Student's $t$-test). 
$50.44 \pm 1.11 \mathrm{pg} / \mathrm{mL}$, respectively. The concentration in LL-EC was higher in PBMC incubated with the $\alpha$-LA and $\beta$-LG mix from bovine milk compared with that from ovine and caprine milks. In ML-EC, IL-1 $\beta$ concentration was higher in PBMC incubated with $\alpha_{\mathrm{S} 1}-\mathrm{CN}$ and $\alpha_{\mathrm{S}_{2}} \mathrm{CN}$ and with the $\alpha$-LA and $\beta-\mathrm{LG}$ mix isolated from bovine milk. In the HL-EC group, production of IL-1 $\beta$ was higher in bovine and ovine $\alpha_{\mathrm{S}_{2}} \mathrm{CN}$ fractions, whereas lower levels were detected for caprine and ovine $\beta-\mathrm{CN}$ and $\kappa-\mathrm{CN}$. Finally, the lowest concentrations of IL-1 $\beta$ were detected in PBMC incubated with the $\alpha$-LA and $\beta$-LG mix in ovine milk and the highest in caprine and bovine milk. Vezzani and Baram (2007) reported an implied role of pro-inflammatory cytokines in seizure activity and epilepsy, with a predominant role of IL-1 $\beta$ as a pro-convulsive cytokine. In the present study, the lower IL-1 $\beta$ response after incubation with caprine $\alpha_{S^{-}}$ $\mathrm{CN}$ fraction could be ascribed to a more complex polymorphism of this casein fraction in goats. Albenzio et al. $(2012,2016 \mathrm{c})$ found high numbers of alleles at the 4 casein loci in goat milk. Genetic polymorphisms of milk proteins play an important role in eliciting different degrees of allergic reaction (El-Agamy, 2007); caseins, especially $\alpha-\mathrm{CN}$, are among the most important milk allergens (Restani et al., 1999; Ballabio et al., 2011). The PBMC of children with cow milk allergy stimulated with casein and $\beta$-LG from bovine milk showed higher TNF- $\alpha$ levels than the same cells stimulated with proteins from caprine milk (Albenzio et al., 2012), indicating a role of pro-inflammatory cytokines such as TNF- $\alpha$ in the immunological reaction to milk proteins. Evaluating the production of cytokines by PBMC after exposure with milk protein fraction is of great interest to identify potential antigens in milk. It is worth noting that $\alpha_{\mathrm{S}_{2}} \mathrm{CN}$ and $\beta$-LG are absent in human milk and that the proportion of caseins and whey protein fractions is different in milk during different phases of lactation (Armaforte et al., 2010).

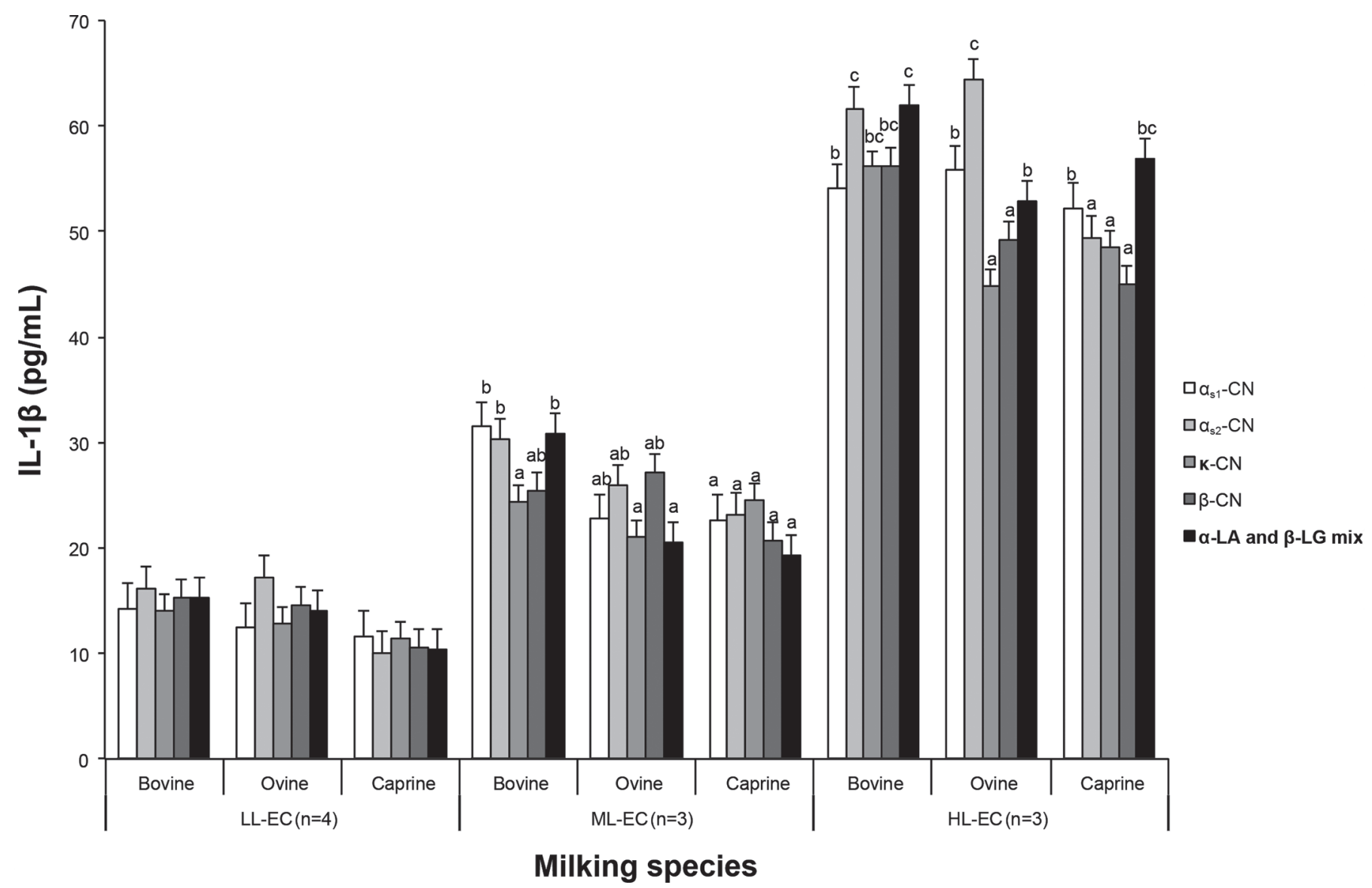

Figure 4. Concentration $(\mu \mathrm{g} / \mathrm{mL})$ of IL-1 $\beta$ produced by peripheral blood mononuclear cells after incubation with milk protein fractions ( $\kappa$ $\mathrm{CN}, \alpha_{\mathrm{S}^{2}} \mathrm{CN}, \alpha_{\mathrm{S} 1}-\mathrm{CN}, \beta-\mathrm{CN}$, and a mix of $\alpha-\mathrm{LA}$ and $\beta-\mathrm{LG}$ ) from different species (bovine, ovine, and caprine). LL-EC (n =4) = group of children with epilepsy having low levels of cytokines not different from those of control children; ML-EC $(\mathrm{n}=3)=$ group of children with epilepsy having cytokine levels at least 5-fold higher (medium levels) than those of control children; HL-EC $(\mathrm{n}=3)=$ group of children with epilepsy having cytokine levels at least 10-fold higher (high levels) than those of control children. Error bars represent SEM. Mean values with different letters $(\mathrm{a}-\mathrm{c})$ differ within a group and species at $P<0.05$ (Student's $t$-test). 


\section{IL-6 Produced by Cultured PBMC of Children with Generalized Epilepsy}

The production of IL- 6 by PBMC after incubation with milk protein fractions from different species is reported in Figure 5. The concentration of IL-6 was affected by species $(P<0.01)$ and by an interaction between species and milk protein fraction $(P<0.05)$. There have been conflicting reports on the influence of IL-6 in seizures. Indeed, it remains unclear whether elevated blood levels of IL-6 allow conclusions to be drawn regarding the expression and function of IL- 6 in epileptogenic brain areas (Li et al., 2011), probably because this cytokine penetrates the blood-brain barrier poorly (Kalueff et al., 2004). Other research reported that elevated levels of IL-6 occurred in the plasma and cerebrospinal fluid of patients with recent epileptic seizures, in which the levels of IL-6 generally correlate with the severity of seizure (Kalueff et al., 2004).
We detected differences in IL-6 production among milking species $(P<0.01)$; IL-6 concentration was lower for caprine, intermediate for ovine, and higher for bovine milk (160.40, 211.14, and $234.31 \pm 22.97$ $\mathrm{pg} / \mathrm{mL}$; mean $\pm \mathrm{SEM})$ in the LL-EC group, whereas IL-6 concentration was lower in ovine and caprine milks than in bovine milk $(1,266.38,1,245.12$, and 1,347.86 \pm $29.81 \mathrm{pg} / \mathrm{mL}$; mean $\pm \mathrm{SEM}$ ) in the HL-EC group. No differences by milking species were found in the ML-EC group, where IL-6 reached a mean level of $662.6 \pm 44$ $\mathrm{pg} / \mathrm{mL}$ in response to bovine, ovine, or caprine milk.

In the ML-EC group, the $\alpha_{\mathrm{S}^{2}} \mathrm{CN}$ fraction from bovine milk resulted in the highest concentration of IL-6 $(P<0.05)$. No differences in IL-6 concentration were observed in the HL-EC group after incubation with $\alpha_{\mathrm{S} 1}-\mathrm{CN}$ and $\beta$-CN. Concentrations of IL-6 were higher in cultured PBMC incubated with $\alpha_{\mathrm{S}^{2}} \mathrm{CN}$ from bovine and ovine milks than in that from caprine milk. The concentration of IL-6 was higher after incubation with

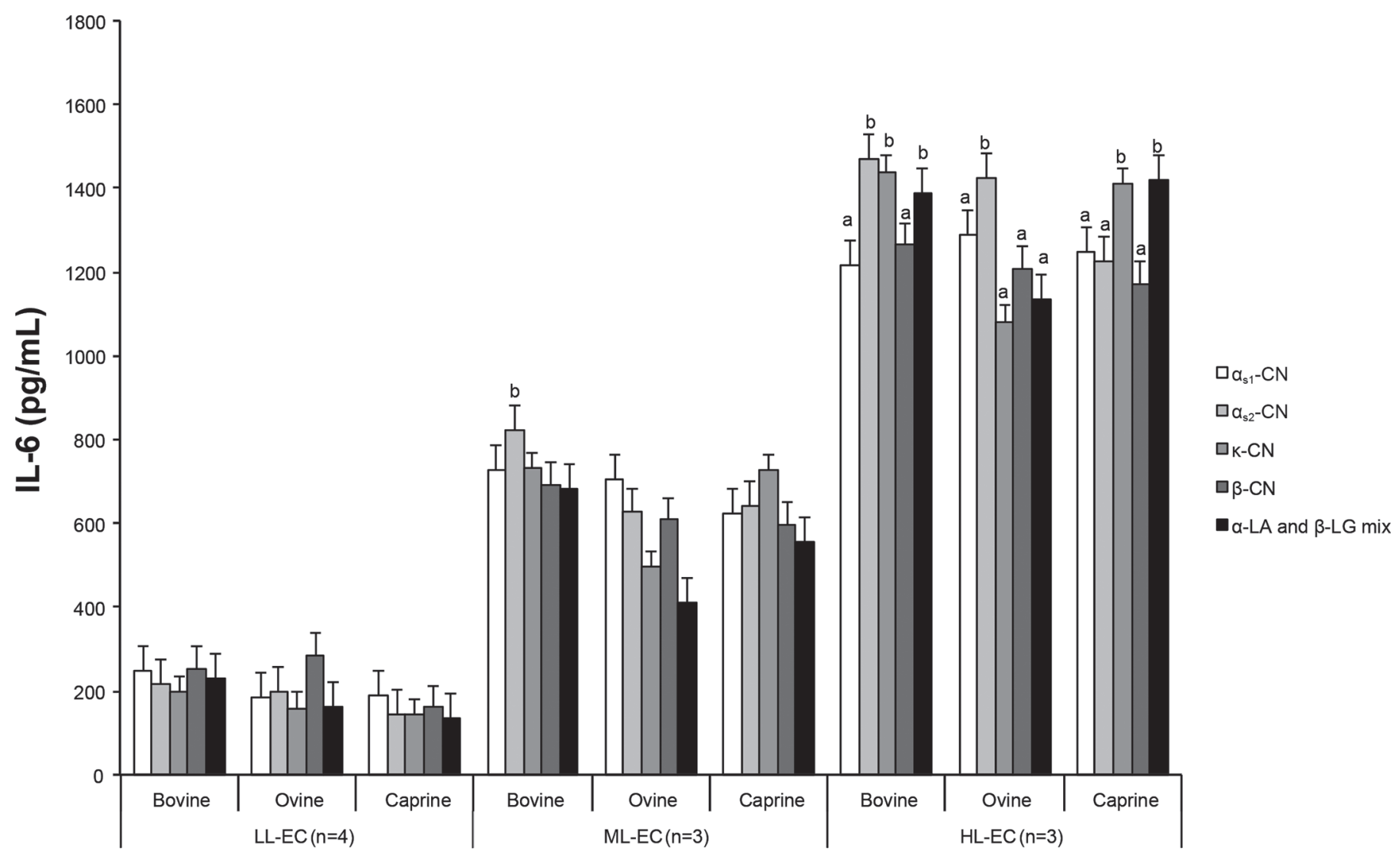

Milking species

Figure 5. Concentration $(\mu \mathrm{g} / \mathrm{mL})$ of IL-6 produced by peripheral blood mononuclear cells after incubation with milk protein fractions ( $\kappa$-CN, $\alpha_{\mathrm{S} 2}-\mathrm{CN}, \alpha_{\mathrm{S} 1}-\mathrm{CN}, \beta-\mathrm{CN}$, and a mix of $\alpha-\mathrm{LA}$ and $\beta-\mathrm{LG}$ ) from different species (bovine, ovine, and caprine). LL-EC ( $\left.\mathrm{n}=4\right)=$ group of children with epilepsy having low levels of cytokines not different from those of control children; ML-EC ( $\mathrm{n}=3)=$ group of children with epilepsy having cytokine levels at least 5 -fold higher (medium levels) than those of control children; HL-EC $(\mathrm{n}=3)=$ group of children with epilepsy having cytokine levels at least 10-fold higher (high levels) than those of control children. Error bars represent SEM. Mean values with different letters $(\mathrm{a}, \mathrm{b})$ differ within a group and species at $P<0.05$ (Student's $t$-test). 
$\kappa-\mathrm{CN}$ and with the $\alpha-\mathrm{LA}$ and $\beta-\mathrm{LG}$ mix from bovine and caprine milks than from ovine milk. In a previous study, Albenzio et al. (2016b) found lower levels of IL-6 in cultured PBMC, from children with epilepsy, incubated with whole casein fractions from caprine milk than bovine and ovine milk. The ability of caprine milk to induce lower expression of IL-6 than bovine and ovine milk may be influenced by the polymorphic nature of $\alpha_{\mathrm{S}^{2}} \mathrm{CN}$ fraction.

\section{IL-10 Produced by Cultured PBMC of Children with Generalized Epilepsy}

We observed no differences in production of IL-10 among milking species $(1.59 \pm 0.19,1.57 \pm 0.21$, and $1.55 \pm 0.18 \mathrm{pg} / \mathrm{mL}$; mean $\pm \mathrm{SEM})$ in cultured PBMC incubated with bovine, ovine, and caprine milks, respectively. Interleukin-10 is one of the major cytokines produced by regulatory $\mathrm{T}$ cells, and it exerts inhibitory actions on monocytes and $\mathrm{T}$ cells, partly suppressing the formation of pro-inflammatory cytokines (Reuss et al., 2002). In this study, all patients with generalized epilepsy produced levels of IL-10 comparable with those of controls, demonstrating the ability of PBMC to exert an anti-inflammatory response when exposed to different protein fractions from bovine, ovine, and caprine milks. In agreement, no differences in plasma IL-10 were found between patients with febrile seizures and controls (Virta et al., 2002). Tiemessen et al.
(2004) investigated the role of IL-10 in T-cell reactivity of children with cow milk allergy, and suggested that activated allergen-specific $\mathrm{T}$ cells might contribute to an active form of immune suppression in vivo through the production of IL-10 and thereby prevent aberrant reactions toward antigens such as cow milk proteins.

\section{Oxidative Status in Cultured PBMC of Children with Generalized Epilepsy}

The effects of milk protein fractions from different species on ROS/RNS levels in cultured PBMC from children with epilepsy are reported in Figure 6. The level of ROS/RNS was affected by species $(P<0.001)$ and the interaction between species and milk protein fractions $(P<0.001)$. The lowest level of ROS/RNS was found in PBMC incubated with the $\alpha$-LA and $\beta$-LG mix isolated from bovine milk, whereas the highest level was found after incubation with $\beta-\mathrm{CN}$ isolated from bovine milk.

Reactive oxygen species include the superoxide anion, hydrogen peroxide, and hydroxyl radical, which are formed by excitation of the solitary electrons of oxygen; these oxygen species exert detrimental effects on unsaturated fats and proteins in cell membranes (Valko et al., 2007; Keskin Guler et al., 2016). The effects on catalase activity of cultured PBMC after incubation with milk protein fractions from different species are reported in Table 2. Catalase activity was affected

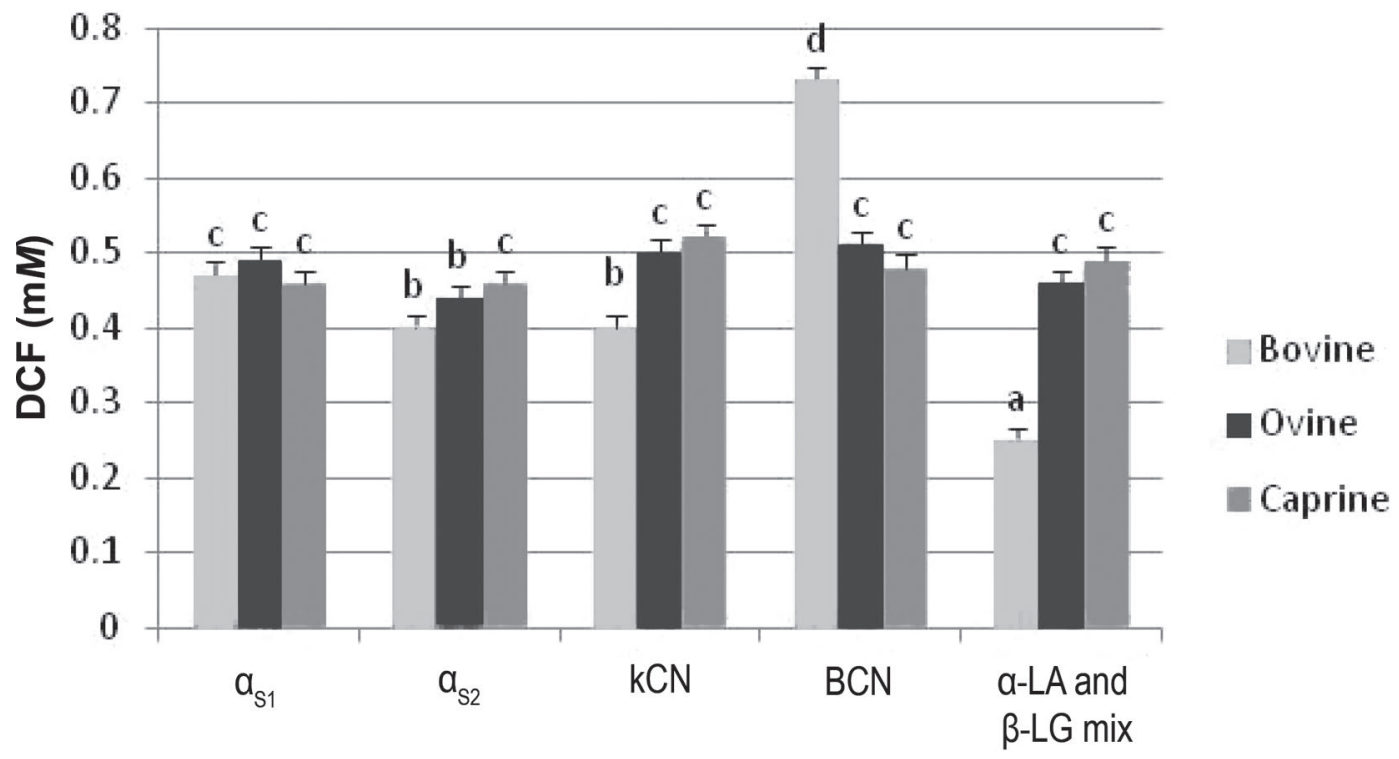

Milk protein fraction

Figure 6. Effects of milk protein fractions from different species on reactive oxygen and nitrogen species levels $(\mathrm{m} M / \mathrm{m})$ in cultured peripheral blood mononuclear cells from children with epilepsy. Error bars represent SEM. Mean values with different letters (a-d) differ within group and species at $P<0.05$ (Student's $t$-test). DCF $=2^{\prime}, 7^{\prime}$-dichlorodihydrofluorescein. 
Table 2. Effects of milk protein fractions from different species on catalase activity $(\mathrm{pg} / \mathrm{mL})$ in cultured peripheral blood mononuclear cells from children with epilepsy

\begin{tabular}{|c|c|c|c|c|c|}
\hline \multirow[b]{2}{*}{ Fraction } & \multicolumn{3}{|c|}{ Milking species } & \multirow[b]{2}{*}{ SEM } & \multirow[b]{2}{*}{ Effect, $P$} \\
\hline & Bovine & Ovine & Caprine & & \\
\hline$\overline{\alpha_{\mathrm{S} 1}-\mathrm{CN}}$ & $15.47^{\mathrm{ab}}$ & $18.52^{\mathrm{bc}}$ & $15.46^{\mathrm{a}}$ & & \\
\hline$\alpha_{S_{2}-} \mathrm{CN}$ & $14.52^{\mathrm{a}}$ & $15.66^{\mathrm{ab}}$ & $15.71^{\mathrm{ab}}$ & & \\
\hline$\beta-\mathrm{CN}$ & $19.11^{\mathrm{c}}$ & $14.90^{\mathrm{a}}$ & $17.81^{\mathrm{bc}}$ & & \\
\hline$\kappa-\mathrm{CN}$ & $13.99^{\mathrm{a}}$ & $13.97^{\mathrm{a}}$ & $14.46^{\mathrm{a}}$ & & \\
\hline Mix of $\alpha-L A$ and $\beta-L G$ & $16.14^{\mathrm{ab}}$ & $15.43^{\mathrm{a}}$ & $16.36^{\mathrm{ab}}$ & 1.03 & $*$ \\
\hline
\end{tabular}

by the interaction between species and milk protein fraction $(P<0.05)$, with higher levels being found in PBMC incubated with the $\beta-\mathrm{CN}$ fraction isolated from bovine and caprine milks and with $\alpha_{\mathrm{S}_{1}} \mathrm{CN}$ from ovine milk. In contrast, lower levels of catalase activity were found after incubation with $\kappa$-CN from all milking species tested and with $\beta$-CN and the $\alpha-\mathrm{LA}$ and $\beta-\mathrm{LG}$ mix isolated from ovine milk.

Catalase is part of the antioxidant system that functions to neutralize ROS produced in the body; specifically, catalase is involved in the breakdown of $\mathrm{H}_{2} \mathrm{O}_{2}$. Recently, Keskin Guler et al. (2016) investigated the oxidant and antioxidant status of patients with epilepsy in relation to its balance in antiepileptic therapy. The higher catalase activity after incubating PBMC with $\beta$-CN and $\alpha_{S_{1}-} \mathrm{CN}$ in the current study might be related to the need to neutralize the highest accumulation of ROS/RNS in the corresponding fraction.

\section{CONCLUSIONS}

In the human newborn, nutrition from milk ensures growth and development during the first stages of life; however, protein components of milk may be related to immune disorders observed in children with generalized epilepsy. Pro- and anti-inflammatory cytokines produced ex vivo from PBMC isolated from children with generalized epilepsy were influenced by stimulation with milk protein fractions from different milking species. The differences in cytokine responses may be associated with genetic polymorphisms of the milk proteins. Evaluating the production of cytokines by PBMC after exposure to different milk protein fraction is of interest to identify potential antigens in milk. In particular, the $\beta$-CN fraction induced the highest levels of TNF- $\alpha$ in ovine and caprine milk, whereas the $\alpha_{S^{-}}$ $\mathrm{CN}$ fraction from bovine milk stimulated the highest level of IL-6 and played a major role in production of IL-1 $\beta$ from cultured PBMC. The higher levels of ROS/ RNS found after stimulation of PBMC with $\beta-\mathrm{CN}$ and $\alpha_{S 1}-\mathrm{CN}$, together with higher catalase activity, may be related to an oxidative stress response in children with generalized epilepsy. Further in vivo studies should be performed to evaluate the influence of milk protein fractions on gut microbiota in the pathophysiology of epilepsy.

\section{ACKNOWLEDGMENTS}

The present work was supported by Fondazione Cassa di Risparmio di Puglia (Bari, Italy). The research is part of the project titled "Focus on protein patterns in milk from different species: relationship between protein fractions and inflammatory response in human" [Studio del profilo proteico del latte di specie diverse: relazioni tra le frazioni proteiche e la risposta infiammatoria nell'uomo.].

\section{REFERENCES}

Albenzio, M., A. Campanozzi, M. D'Apolito, A. Santillo, M. Pettoello Mantovani, and A. Sevi. 2012. Differences in protein fraction from goat and cow milk and their role on cytokine production in children with cow's milk protein allergy. Small Rumin. Res. 105:202-205

Albenzio, M., A. N. Polito, and A. Santillo. 2016a. The role of milk nutrition in childhood epilepsy. Int. J. Food Nutr. Sci. 5:141-150.

Albenzio, M., A. Santillo, M. Avondo, A. Nudda, S. Chessa, A. Pirisi, and S. Banni. 2016c. Nutritional properties of small ruminant food products and their role on human health. Small Rumin. Res. 135:3-12.

Albenzio, M., A. Santillo, M. G. Ciliberti, L. Figliola, M. Caroprese, R. Marino, and A. N. Polito. 2016b. Milk from different species: Relationship between protein fractions and inflammatory response in infant affected by generalized epilepsy. J. Dairy Sci. 99:5032-5038.

Albers, R., J. M. Antoine, R. Bordet-Sicard, P. C. Calder, M. Gleeson, B. Lesourd, S. Samartin, I. R. Sanderson, J. Van Loo, F. W. Vas Dias, and B. Watzl. 2005. Markers to measure immunomodulation in human nutrition intervention studies. Br. J. Nutr. 94:452-481.

Armaforte, E., E. Curran, T. Huppertz, C. A. Ryan, M. F. Caboni, P. M. O'Connor, R. P. Rosse, C. Hirtzf, N. Sommererf, and F. Chevalier. 2010. Proteins and proteolysis in pre-term and term human milk and possible implications for infant formulae. Int. Dairy J. 20:715-723.

Ballabio, C., S. Chessa, D. Rignanese, C. Gigliotti, G. Pagnacco, and L. Terracciano. 2011. Goat milk allergenicity as function of $\alpha_{\mathrm{S}^{-}}$ casein polymorphism. J. Dairy Sci. 94:998-1004.

Bobe, G., D. C. Beitz, A. E. Freeman, and G. L. Lindberg. 1998. Separation and quantification of bovine milk proteins by reverse-phase 
high-performance liquid chromatography. J. Agric. Food Chem. 46:458-463.

Damsgaard, C. T., L. Lauritzen, P. C. Calder, T. M. R. Kjær, and H. Frøkiær. 2009. Whole-blood culture is a valid low-cost method to measure monocytic cytokines-A comparison of cytokines production in cultures of human whole-blood, mononuclear cells and monocytes. J. Immunol. Methods 340:95-101.

Dario, C., D. Carnicella, M. Dario, and G. Bufano. 2008. Genetic polymorphism of $\beta$-lactoglobulin gene and effect on milk composition in Leccese sheep. Small Rumin. Res. 74:270-273.

Duncan, J. S., J. W. Sander, S. M. Sisodiya, and M. C. Walker. 2006. Adult epilepsy. Lancet 367:1087-1100.

El-Agamy, E. I. 2007. The challenge of cow milk protein allergy. Small Rumin. Res. 68:64-72.

Falsaperla, R., P. Pavone, S. Miceli Sopo, F. Mahmood, F. Scalia, G. Corsello, R. Lubrano, and G. Vitaliti. 2014. Epileptic seizures as a manifestation of cow's milk allergy: A studied relationship and description of our pediatric experience. Expert Rev. Clin. Immunol. 10:1597-1609.

Galic, M. A., K. Riazi, and Q. J. Pittman. 2012. Cytokines and brain excitability. Front. Neuroendocrinol. 33:116-125.

Guo, H. Y., K. Pang, X. Y. Zhang, L. Zhao, S. W. Chen, M. L. Dong, and F. Z. Ren. 2007. Composition, physicochemical properties, nitrogen fraction distribution, and amino acid profile of donkey milk. J. Dairy Sci. 90:1635-1643.

Gutcher, I., and B. Becher. 2007. APC- derived cytokines and T cell polarization in autoimmune inflammation. J. Clin. Invest. 117:1119-1127.

Kalueff, A. V., K. A. Lehtimaki, A. Ylinen, J. Honkaniemi, and J. Peltola. 2004. Intranasal administration of human IL-6 increases the severity of chemically induced seizures in rats. Neurosci. Lett. 365:106-110

Keskin Guler, S., B. Aytac, Z. E. Durak, B. G. Cokal, N. Gunes, I. Durak, and T. Yoldas. 2016. Antioxidative-oxidative balance in epilepsy patients on antiepileptic therapy: A prospective casecontrol study. Neurol. Sci. 37:763-767.

Laemmli, U. K. 1970. Cleavage of structural proteins during the assembly of the head of bacteriophage T4. Nature 227:680-685.

Leitner, G., M. Chaffer, A. Shamay, F. Shapiro, U. Merin, E. Ezra, A. Saran, and N. Silanikove. 2004. Changes in milk composition as affected by subclinical mastitis in sheep. J. Dairy Sci. 87:46-52.

Li, G., S. Bauer, M. Novak, B. Norwood, B. Rosenow, S. Knake, W. H. Oertel, and H. M. Hamer. 2011. Cytokines and epilepsy. Seizure 20:249-256.
Marchi, N., Q. Fan, C. Ghosh, V. Fazio, F. Bertolini, G. Betto, A. Batra, E. Carlton, I. Najm, T. Granata, and D. Janigro. 2009. Antagonism of peripheral inflammation reduces the severity of status epilepticus. Neurobiol. Dis. 33:171-181.

Ong, M. S., I. S. Kohane, T. Cai, M. P. Gorman, and K. D. Mandl. 2014. Population-level evidence for an autoimmune etiology of epilepsy. JAMA Neurol. 71:569-574.

Palace, J., and B. Lang. 2000. Epilepsy: An autoimmune disease? J. Neurol. Neurosurg. Psychiatry 69:711-714.

Pollak, T. A., T. R. Nicholson, J. D. C. Mellers, A. Vincent, and A. S. David. 2014. Epilepsy-related psychosis: A role for autoimmunity? Epilepsy Behav. 36:33-38.

Restani, P., A. Gaiaschi, A. Plebani, B. Beretta, G. Cavagni, A. Fiocchi, C. Poiesi, T. Velonà, A. G. Ugazio, and C. L. Galli. 1999 Cross-reactivity between milk proteins from different animal species. Clin. Exp. Allergy 29:997-1004.

Reuss, E., R. Fimmers, A. Kruger, C. Becker, C. Rittner, and T. Höhler. 2002. Differential regulation of interleukin-10 production by genetic and environmental factors - A twin study. Genes Immun. 3:407-413.

Riazi, K., M. A. Galic, and Q. J. Pittman. 2010. Contributions of peripheral inflammation to seizure susceptibility: Cytokines and brain excitability. Epilepsy Res. 89:34-42.

SAS Institute. 2011. SAS User's Guide: Statistics. Version 9.2 ed. SAS Inst. Inc., Cary, NC.

Shapiro, S. S., and M. Wilk. 1965. An analysis of variance test for normality. Biometrika 52:591-601.

Tiemessen, M. M., A. G. van Ieperen-Van Dijk, C. A. F. M. Bruijnzeel-Koomen, J. Garssen, E. F. K. Knol, and E. V. Van Hoffen 2004. Cow's milk-specific T-cell reactivity of children with and without persistent cow's milk allergy: Key role for IL-10. J. Allergy Clin. Immunol. 113:932-939.

Valko, M., D. Leibfritz, J. Moncol, M. T. Cronin, M. Mazur, and J. Telser. 2007. Free radicals and antioxidants in normal physiological functions and human disease. Int. J. Biochem. Cell Biol. 39:44-84.

Vezzani, A., and T. Z. Baram. 2007. New roles for interleukin-1 beta in the mechanism of epilepsy. Epilepsy Curr. 7:45-50.

Virta, M., M. Hurme, and M. Helminen. 2002. Increased plasma levels of pro- and anti- inflammatory cytokines in patients with febrile seizures. Epilepsia 43:920-923.

Wu, J., Y. Zhang, Y. Rao, J. Miao, and X. Lu. 2016. Intestinal microbiota as an alternative therapeutic target for epilepsy. Can J. Infect Dis. Med. Microbiol. 2016:9032809. https://doi.org/10 $.1155 / 2016 / 9032809$ 